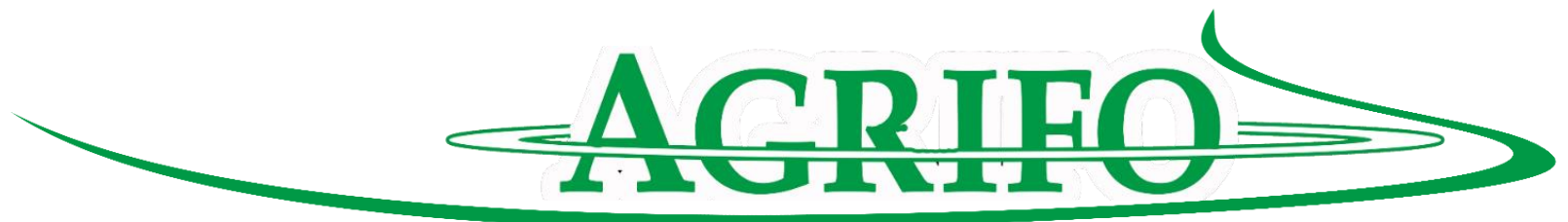

\title{
PERSEPSI PETANI LADA ACEH TERHADAP PELAKSANAAN PENYULUHAN PERTANIAN KERJASAMA PERGURUAN TINGGI
}

(Studi Kasus: Kelompok Petani Lada Pulo Iboih)

\author{
Setia Budi ${ }^{1}$ \\ email: setiabudi@unimal.ac.id
}

\begin{abstract}
ABSTRAK
Secara umum penelitian ini bertujuan untuk mendapatkan data dasar (data base) tentang model kegiatan pemberdayaan melalui penyuluhan pertanian kerja sama perguruan tinggi dengan masyarakat tani Gampong Pulo Iboih sebagai desa binaan Universitas Malikussaleh. Secara khusus penelitian ini bertujuan untuk mengetahui persepsi petani lada terhadap pelaksanaan penyuluhan kerjasama perguruan tinggi di Gampong Pulo Iboih. Metode penelitian yang digunakan dalam penelitian ini metode penelitian kualitatif studi kasus pada kelompok petani lada dan pengolahan datanya statistik non parametric dengan pengukuran data mengunakan skala likert. Hasil penelitian menunjukkan persepsi petani lada terhadap penyuluh pertanian yang sangat baik dirasakan oleh petani lada Gampong Pulo Iboih, secara berurutan meliputi; (1) peran penyuluh dalam melakukan pelatihan budidaya, (2), peran penyuluh sebagai pihak penghubung antara petani lada dengan pihak luar (3) peran penyuluh pertanian perecanaan dan pengawasan program budidaya lada serta (4) peran penyuluh dalam penguatan kelompok. Pesepsi petani Petani lada terhadap peran penyuluh dari perguruan tinggi dalam tahapan proses penyuluhan pertanian pada pelaksanaan penyuluhanan pertanian secara berurutan meliputi; (1) ketepatan pengunaan media, (2) kesesuaian metoda penyuluhan, (3) kesesuaian materi penyuluhan dan (4) intensitas pelaksanaan penyuluhan.
\end{abstract}

Kata Kunci : persepsi, peran penyuluh, perguruan tinggi, petadi lada

\section{PENDAHULUAN}

Hakekatnya petani merupakan pelaku utama pembangunan pertanian. Dengan demikian keberhasilan pembangunan pertanian lebih banyak ditentukan oleh peranan petani itu sendiri yang dalam kenyataannya tidak terlepas dari bimbingan dan bantuan pemerintah dan berbagai pihak.

Selain petani Menurut Mosher (1987) salah satu syarat pokok dalam pembangunan pertanian adalah teknologi yang senantiasa berubah. Oleh sebab itu, inovasi memegang peranan sangat penting dalam pembangunan pertanian. Pihak yang selama ini sangat berperan dalam proses transfer inovasi kepada petani adalah penyuluh pertanian.

Kurnia Suci Indraningsih (2010) menyatakan bahwa peran penyuluh pertanian hanya dapat dirasakan oleh pengurus kelompok tani saja. Curahan waktu lebih banyak untuk kegiatan yang bersifat administratif dibandingkan dengan kegiatan penyuluhan, serta beban wilayah binaan mencapai 3-6 desa untuk masing-masing penyuluh.

\footnotetext{
${ }^{1}$ Staff Pengajar Program Studi Agribisnis Universitas Malikussaleh
} 
Penyuluhan pertanian harus mampu menyiapkan, menyediakan dan menyajikan segala informasi yang diperlukan oleh para petani. Informasiinformasi tentang berbagai komoditas pertanian dan informasi lain yang berhubungan dengan pengolahan dan pemasarnya perlu dipersiapkan dan dikemas dalam bentuk dan bahasa yang mudah dimengerti oleh para petani (Margono Slamet, 2003).

Aspek lain yang tidak kalah pentingnya bagi penyuluh setelah programa terbentuk adalah mempersiapkan materi dan metoda serta media penyuluhan yang dipilih dan digunakan dalam pelaksanaan penyuluhan pertanian. Pencapaian tujuan akhir dari penyuluhan sangat ditentukan materi, metode serta ketepatan pengunaan media oleh seorang penyuluh (Sapar, 2012).

Kondisi ini membutuhkan adanya usaha berbagai pihak termasuk dari pihak perguruan tinggi untuk melakukan kegiatan pemberdayaan masyarakat melalui kegiatan penyuluh pertanian untuk mengoptimalkan pendistribusikan/desiminasi inovasi kepada petani yang dihasilkan dalam kegiatan penelitian ilmiah untuk peningkatan ketrampilan petani dalam proses Petani budidaya komoditi pertanian khususnya budidaya lada Aceh.

\section{METODE PENELITIAN}

Penelitian ini dilaksanakan di Kabupaten Aceh Utara tepatnya di Gampong Pulo Iboih Kecamatan Kuta Makmur. Populasi penelitian ini meliputi seluruh Petani Lada anggota Gapoktan 'Tuah Meugoe yang mendapatkan program kemitraan penyuluhan pertanian dari Penguruan Tinggi Universitas Malikussaleh (Unimal). Keseluruhan populasi menjadi sampel dalam penelitian ini yang berjumlah 32 petani.

Ruang lingkup penelitian dibatasi hanya melihat peran penyuluh pertanian dalam pelaksanaan penyuluhan pertanian pada Petani Lada. Objek penelitian adalah Petani Lada anggota gapoktan yang memberikan penilaian terhadap peran penyuluh dalam pelaksanaan penyuluhan kepada Petani Lada di Gampong Pulo Iboih Kecamatan Kuta Makmur Kabupaten Aceh Utara.

Untuk mengukur dan menganalisis peran penyuluhan pertanian dari perguruan tinggi kepada petani lada dilakukan dengan mengunakan pengukuran data skoring skala likert meliputi (1) peran penyuluh dalam melakukan pelatihan budidaya, (2) peran penyuluh dalam penguatan kelompok, (3) peran penyuluh sebagai pihak penghubung antara petani Petani dengan pihak luar (mitra usaha),serta (4) peran penyuluh pertanian perecanaan dan pengawasan kegiatan Budidaya lada Aceh.

Analisis Peran para mitra dalam pelaksanan penyuluhan pertanian dengan indicator (1) kesesuaain materi, (2) Kesesuaian metoda penyuluhan (3) ketepatan pengunaan media dan (4) instensitas penyuluhan yang dilakukan oleh para mitra yang selanjutnya diinterpretasi dalam pembahasan.

Menurut Riduwan (2003) dan Nasir M (2003) kriteria interpretasi skor likert:

1. Angka 0\%-19\% = Sangat tidak baik

2. Angka $20 \%-39,99 \%=$ Kurang baik

3. Angka 40\%- 59,99\% = cukup

4. Angka $60 \%-79,99 \%=$ Baik 
5. Angka $80 \%-100 \%=$ Sangat baik

\section{HASIL DAN PEMBAHASAN}

Pelaksanaan pemberdayaan petani lada melalui kegiatan penyuluhan pertanian di Gampong Pulo Iboih Kecamatan Kuta Makmur Kabupaten Aceh Utara berawal dari pelaksanaan MOU Desa Binaan tahun 2016 antara Gampong Pulo Iboih dengan Pihak Universitas Malikussaleh yang kemudian ditindak lanjuti oleh Pihak Lembaga Penelitian dan Pengabdian Pada Masyarakat (LPPM) Universitas Malikussaleh. Berdasarkan observasi dan telaahan potensi gampong maka yang dilakukan maka selain subsektor pertanian tanaman pangan, susektor perkebunan budidaya lada Aceh juga potensial untuk dikembangkan, mengingat adanya masyarakat yang mengembangnkan komoditi lada Aceh di Gampong Pulo Iboih.

Setelah pemetaaah kondisi dan musyawarah bersama antara petani lada dengan pihak LPPM Universitas Malikussaleh disepakatilah untuk merencanakan dan melaksanakan program penyuluhan pertanian untuk pemberdayaan anggota kelompok tani lada. Tahapan pelaksanaanpenyuluhan yang dilakukan oleh pihak LPPM Unimal dengan melibatkan sejumlah pihak dalam percepatan pencapaian tujuan program ini dipersepsikan secara bervariasi oleh petani lada Aceh di Gampong Pulo Iboih.

Petani Lada mempersepsikan secara umum peran penyuluh berada pada kategori baik. Peran Penyuluh berdasarkan keseluruhan indikator yang dilihat dalam penelitian ini dapat dilihat pada Tabel 1. Berikut:

Tabel 1. Nilai Indeks Persepsi Petani Lada Dalam Pelaksanaan Penyuluhan

\begin{tabular}{llll}
\hline No & Peran penyuluh & Indeks (\%) & Interpretasi \\
\hline 1 & $\begin{array}{l}\text { Peran penyuluh dalam penguatan } \\
\text { kelompok }\end{array}$ & 70.14 & Baik \\
2 & $\begin{array}{l}\text { Peran Penyuluh dalam Kegiatan } \\
\text { Pelatihan budidaya Lada }\end{array}$ & Sangat Baik \\
3 & $\begin{array}{l}\text { Peran Penyuluh dalam Perencanaan } \\
\text { dan pengawasan Program Budidaya }\end{array}$ & 72.32 & Baik \\
& $\begin{array}{l}\text { Lada } \\
\text { Peran penyuluh sebagai Pihak } \\
\text { Penghubung dengan Pihak luar }\end{array}$ & Sangat Baik \\
\hline & Persepsi Umum & 78.74 & Baik \\
\hline
\end{tabular}

Sumber; Analisis data primer (2017)

Tabel 1 menunjukkan persepsi petani terhadap pelaksanaan penyuluh dalam kegiatan pelatihan budidaya lada berada pada kategori sangat baik. pelatihan selama dua kali yang dilakukan penyuluh meliputi, motivasi usaha budidaya lada Aceh dengan pemaparan potensi dan peluang usaha budidaya lada. selanjutnya dengan pendekatan metode Anjang Karya ke pusat pembibitan lada Aceh CV. Agro Indatu Mulya Petani mendapatkan bekal ilmu budidaya lada Aceh dari LPPM dan Petani Andalan meliputi : Cara pembibitan, Budidaya lada perdu, Budidaya lada Sulur dan Budidaya lada dalam media Pot (perdu dan Sulur). Setelah pelatihan petani juga dibekali 
dengan bantuan bibit lada unggul untuk dibudidaya di Gampong Pulo Iboih. Menurut Petani pelatihan yang dilakukan penyuluh dirasakan mamfaat untuk mendukung peningkatan

ketrampilan budidaya Petani Lada.

Penyuluhan pertanian yang dilakukan oleh pihak LPPM Unimal sangat baik sebagai penghubung petani lada dengan pihak luar. Pihak luar yang dimaksud oleh petani antara lain menjembatani petani lada untuk dapat belajar ketrampilan budidaya lada Aceh kepada petani yang sudah berhasil seperti pada CV. Indatu Mulya yang difasilitasi oleh Pihak LPPM Unimal. Pihak LPPM Unimal juga menfasilitasi kelompok Petani lada Gampong Pulo Iboih untuk menyampaikan aspirasi dari petani melalui media Radio Republik Indonesia (RRI) Kota Lhokseumawe melalui Program RRI membangun gampong dan ini diyakini oleh petani sebagai ajang memperkenalkan komoditas petani lada Aceh dan juga menyampaikan permasalahan yang dihadapi kepada pihak pemerintah dan stakeholder lainya untuk pengembangan komoditi lada Aceh di Gampong Pulo Iboih.

Dalam aspek penyuluhan untuk penguatan kelompok baik berkaitan tertib administrasi kelompok, serta adanya pertemuan tersruktur yang menjadi wadah bagi petani lada Aceh untuk berbagi informasi dan mendiskusikan berbagai masalah yang dihadapi oleh anggota kelompok tani yang bergabung dalam kelompok tani lada Aceh " Tuah Meugoe" berada pada kategori baik. Penguatan kelompok yang dilakukan penyuluh memotivasi petani untuk mengunakan lembaga kelompok tani dalam mendukung kegiatan budidaya lada Aceh yang diusahakannya. Walaupun belum ada agenda pertemuan yang terjadwal namun inisiatif dari anggota kelompok petani lada untuk berdiskusi dalam wadah kelompok tani sudah mulai tumbuh seiring dengan dirasakannya manfaat adanya kelompok tani dalam mendukung kegiatan budidaya lada yang diusahakannya.

Kondisi yang hampir sama juga dipersepsikan petani berkaitan dengan peran penyuluh dalam merencanakan dan pengawasan program budidaya lada Aceh sebahagian petani merasa kurang dilibatkan dalam merencanakan program misalnya pada pemilihan petani yang terlibat (ikut) kegiatan anjang karya ke petani berhasil yang dilaksanakan LPPM Unimal untuk meningkatkan ketrampilan budidaya lada anggota kelompok tani. Berkaitan dengan perencanaan dan persepsi petani tentang perencanaan dan pengawasan program ini dapat dimaklumi karena belum belum berperannya kelompok secara baik dalam menerapkan mekanisme perencanaan dan sosialisasi kegiatan yang tidak mampu memenuhi kebutuhan semua anggota kelompok.

Pada penelitian ini juga didapatkan gambaran peran penyuluh dalam pelaksanan penyuluhan kepada Petani Lada meliputi indicator; kesesuaian materi penyuluhan, metode penyuluhan, ketepatan pengunaan media dan intensitas pelaksanaan penyuluhan. Hasil indek persepsi petani terhadap peran penyuluh dari perguruan tinggi dalam pelaksanaan penyuluhan dapat dilihat pada tabel 2 berikut: 
Tabel 2. Nilai Indeks Persepsi Petani Terhadap Peran Penyuluh dalam Pelaksanaan Penyuluhan

\begin{tabular}{llll}
\hline No & Pelaksanan Penyuluhan Pertanian & Indeks (\%) & Interpretasi \\
\hline 1 & Materi Penyuluhan & 82.26 & Sangat Baik \\
2 & Metode Penyuluhan & 84.37 & Sangat Baik \\
3 & Ketepatan pengunaan media & 84.79 & Sangat Baik \\
4 & Intensitas pelaksanaan penyuluhan & 70.66 & Baik \\
\hline \multirow{2}{*}{} & Persepsi Umum & 80.51 & Sangat Baik
\end{tabular}

Analisis data primer (2016)

Petani Lada Aceh Gampong Pulo Iboih berpersepsi materi penyuluhan yang disampaikan para penyuluh sangat baik (sesuai) dengan kebutuhannya. Pemberian materi diberikan secara bertahap sesuai dengan proses budidaya dan kebutuhan usahatani yang lakukan petani mulai dari memunculkan kesadaran usaha, motivasi usaha, tahapan budidaya, pengelolaan hasil panen, pemasaran dan penguatan kelompok. Materi yang diberikan oleh penyuluh dari Pihak Perguruan Tinggi (LPPM Unimal) yang juga dibarengi dengan proses pedampingan dalam penerapan inovasi teknologi budidaya Lada Aceh untuk pengembangan usahatani lada Aceh. Kondisi ini sesuai dengan Burn R, (1993), Agussabti (2005) untuk memastikan inovasi diadpsi oleh petani perlu dilakukan proses pendampingan menuju kemandirian petani.

Metoda penyuluhan yang digunakan mulai dengan ceramah, demontrasi cara, Anjang karya sangat baik dirasakan mamfaatnya oleh petani lada Aceh.Variasi metode penyuluhan dipersepsikan petani lada Aceh menjadi efektif dalam memenuhi kebutuhan petani budidaya lada Aceh. Metode yang langsung bisa memberikan bukti nyata atas penerapan teknologi budidaya melalui metoda penyuluhan Anjang karya ketempat petani yang sudah berhasil dirasakan penting memberikan efektivitas penyerapan inovasi dan informasi oleh petani. Hal ini sejalan dengan Sapar at all (2012) menyatakan pelaksanaan penyuluhan yang berhasil harus mampu pelaksananya (penyuluh) merancang materi dan metode sesuai dengan kebutuhan, kondisi dan karakteristik petani sehingga materi kepemimpinan, diseminasi teknologi dan penguasaan bidang teknis haruslah dikuasai oleh pelaksana penyuluhan.

Aspek ketepatan pengunaan media dari persepsi petani terhadap peran penyuluh pertanian dari perguruan tinggi dalam pelaksanaan penyuluhan kepada Petani Lada. Pada hakekatnya berbagai media penyuluhan dapat digunakan untuk mengemas informasi dan teknologi yang akan disampaikan kepada Petani Lada sebagai pengguna teknologi. Jenis media penyuluhan bisa berupa; media cetak, media audio, media audio visual, media berupa obyek fisik atau benda nyata. Media apapun yang digunakan, pada prinsipnya harus dapat meningkatkan efektivitas dan kelancaran proses belajar terutama dalam memperjelas materi yang dipelajari sehingga dapat mempercepat terjadinya perubahan perilaku (pengetahuan, keterampilan, dan sikap) dikalangan kelompok sasaran. Petani Lada padi 
merasakan penyuluhan yang dilakukan penyuluh dari perguruan tinggi sudah optimal dalam memadukan berbagai jenis media untuk mendukung pelaksanaan penyuluhan dimana masih didominasi oleh media cetak dan radio.

Persepsi petanin tentang intensitas pelaksanaan penyuluhan pertanian yang dilakukan untuk petani lada berada pada ketegori baik. Namun demikian anggota kelompok tani mengharapkan adanya peningkatan intensitas dan hal ini dapat dimaklumi dengan terdapatnya banyak petani pemula yang masih sangat membutuhkan intensitas pelaksanaan penyuluhan tinggi untuk meningkatkan ketrampilan budidaya lada yang diusahakannya. Slamet Margono (2003) intensitas pelaksanaan penyuluhan pertanian dalam pemberdayaan masyarakat disesuaikan dengan kebutuhan khalayah sasaran.

\section{KESIMPULAN}

Peran penyuluh pertanian dari perguruan tinggi secara umum dirasakan sangat baik oleh Petani Lada. Secara berurutan peran penyuluhan pertanian dari penguruan tinggi meliputi; (1) peran penyuluh dalam melakukan pelatihan budidaya lada, (2) peran penyuluh sebagai pihak penghubung antara petani lada Aceh dengan pihak luar (3), peran penyuluh pertanian perecanaan dan pengawasan kegiatan budidaya lada Aceh, serta (4) peran penyuluh dalam penguatan kelompok.

Peran penyuluh dalam pelaksanaan penyuluhanan pertanian kepada petani lada secara berurutan adalah (1) ketepatan pengunaan media menduduki, (2), kesesuaian metoda penyuluhan (3) kesesuaian materi penyuluhan dan (4) intensitas penyuluhan berada pada urutan terakhir.
Perlu perhatian penyuluh dalam kegiatan penyuluhan kepada Petani Lada untuk mencari solusi bagaimana mengoptimalkan peran penyuluh dalam meningkatkan perannya dalam proses perencanaan dan pengawasan kegiatan budidaya lada Aceh yang dilakukan oleh petani lada di Gampong Pulo Iboih.

Peningkatan intensitas pelaksanaan penyuluhan pertanian dari pihak penguruan tinggi untuk menyahuti semangat petani dalam mempercepat terjadinya perubahan perilaku (pengetahuan, keterampilan, dan sikap) dalam penerapan teknologi budidaya lada Aceh.

\section{UCAPAN TERIMA KASIH}

Peneliti mengucapkan terima kasih kepada Rektor Unimal, Pihak LPPM Unimal, dan Aparatur Gampong Pulo Iboih yang telah berkontribusi untuk berlangsungnya penelitiaan ini.

\section{DAFTAR PUSTAKA}

Agussabti.2002. Kemandirian Petani Dalam Pengambilan Keputusan Adopsi Inovasi (kasus Petani Sayuran Di Provinsi Jawa Barat) Disertasi Program Pascasarjana IPB. Bogor.

Buch, R. 1993. Dua Tongkol Jagung: Pedoman Pengembangan Pertanian Berpangkal Pada Rakyat. Yayasan Obor Indonesia. Jakarta

Indraningsih K.S, B.G. Sugihen, P. Tjiptopranoto, P.S. Ansgari. 2010. Performance Of Extension Workers From Famers Perspective and the Existence Of Self- Support Extension. Journal Of Extension (8) 304-321. 
Margono Slamet 2003. Membentuk Pola Prilaku Manusia Pembangunan. Institut Pertanian Bogor. IPB Press. Bogor.

Mosher.A.T . 1987. Mengerakkan dan Membangun Pertanian. CV. Yasaguna Jakarta.

Nazir, M. 2011. Metode Penelitian Cetakan Ke-Tujuh. Ghalia Indonesia. Jakarta.

Roger. E. M and F. Shomaker. 1983. Difusion Of Innovation (Edisi Ketiga). The Free Press : A. Division Of Macmilian. Publishing. Co.Inc.New York.

Riduwan.2003. Skala Pengukuran Variabel-Variabel Penelitian. CV. Alfabeta, Bandung.
Rismunandar. 2003. Lada Budidaya dan Tataniaga Edisi Revisi. Penebar Swadaya. Jakarta.

Rukmana, R. 2003. Usahatani Lada Perdu. Kanisius. Yogyakarta.

Sapar., Amri J., Pang S. A., Amiruddin., I. G Putu P (2012). The Performance Agricultural Extension Workers and their Impact at Competence Cacao Farmers in four District South Sulawesi. Journal Extension. Vol. 8, No. 1, March 2012.

Van Den Ban A.W dan H.S.Hawkins.1999.

Penyuluhan Pertanian. Kanisius. Yogyakarta. 